\title{
Anti-Staphylococcal Enterotoxinogenesis of Lactococcus lactis in Algerian Raw Milk Cheese
}

\author{
Fatiha Tetili ${ }^{1}$, Farida Bendali ${ }^{1 *}$, Josette Perrier ${ }^{2}$ and Djamila Sadoun ${ }^{1}$ \\ ${ }^{1}$ Applied Microbiology Laboratory, Life and Nature Sciences Faculty, Bejaia University, DZ-06000 Bejaia, Algeria \\ ${ }^{2}$ Paul Cézanne Aix-Marseille III University, Group Molecular Interactions Intestinal Mucosal Microbiote, \\ ISM2-Biosciences UMR CNRS 6263, Faculty of Sciences, \\ FR-13397 Marseille Cedex 20, France \\ Received: December 9, 2016 \\ Accepted: October 12, 2017
}

\begin{abstract}
Summary
Staphylococcus aureus is a potential pathogen contaminating raw milk and dairy products, where it is able to produce thermostable enterotoxins that can cause staphylococcal food poisoning. This study was undertaken to investigate the inhibitory activity of a Lactococcus lactis strain (isolated from milk) on S. aureus growth and staphylococcal enterotoxin A (SEA) production. In the presence of $L$. lactis, the number of the pathogen decreased significantly $(\mathrm{p}<0.05)$ after $6 \mathrm{~h}$ of incubation in a laboratory medium and milk $(3 \mathrm{log} \mathrm{CFU} / \mathrm{mL}$ reduction compared to pure cultures). SEA concentration was reduced by $79 \%$ in the co-cultures. S. aureus was unable to reach population levels permitting SEA production in the cheese inoculated with L. lactis during 32 days of storage. In contrast, during the same period, it attained 7 log $\mathrm{CFU} / \mathrm{g}$ in the cheese manufactured without the lactococcal strain, a level which permitted SEA detection in the cheese extracts. However, this enterotoxin was never detected in the cheese harbouring L. lactis. These results demonstrate the anti-staphylococcal enterotoxinogenesis potential of the L. lactis strain and its usefulness in raw milk cheese biopreservation.
\end{abstract}

Key words: Staphylococcus aureus and Lactococcus lactis co-cultures, enterotoxin A, inhibitory activity, milk, cheese, storage

\section{Introduction}

Staphylococcus aureus is recognized as the major causative agent of food poisoning (1), which results from ingestion of foods containing one or more pre-formed toxins. Severe symptoms such as nausea, violent vomiting, diarrhoea and abdominal cramps may be developed by susceptible individuals following consumption of these toxins (2). Milk and dairy products have been incriminated in several outbreaks worldwide (3). Indeed, S. aureus is a common cause of udder diseases in dairy cows. In Algeria, it has been demonstrated that this bacterium is the major etiological agent of clinical and subclinical bovine mastitis $(4,5)$. Presence of enterotoxigenic $S$. aureus strains in milk constitutes a high risk of food intoxication when it is consumed or used for cheese making, especially if no thermal treatment is applied (6). Despite this hazard, some traditional fermented dairy products, including cheese, are still prepared in Algerian households using raw milk.

Besides mastitic milk (7), the processing plant environment and the workers may constitute serious $S$. aureus contamination sources during cheese making $(8,9)$. Presence of S. aureus in milk has been largely reduced by identifying and controlling the potential sources of this species, especially mastitis and lack of hygiene (10). However, $S$. aureus, even when present at low levels in milk, can reach over $5 \log \mathrm{CFU} / \mathrm{g}$ during the early stages of cheese making (11). It was reported that $25 \%$ of S. aureus strains, isolated from food, produced heat-stable enterotoxins $(12,13)$. These toxins are a family of exoproteins forming a 
single chain with low molecular mass, ranging from 26 to $30 \mathrm{kDa}$ (14). Twenty-four different staphylococcal enterotoxins (SEs) and SE-like (SEls) toxins have been reported (15), and most of the genes coding for them have been described $(16,17)$. Contrary to the producer microorganism, these enterotoxins are remarkably heat-resistant; they resist the temperatures which easily destroy the bacteria that produce them as well as the proteolytic enzymes, and hence retain their activity in the digestive tract after ingestion $(18,19)$.

Staphylococcal enterotoxin A (SEA) is responsible for $75 \%$ of staphylococcal food poisoning outbreaks in developed countries (20), followed by staphylococcal enterotoxin D (SED, 37.5\%) and staphylococcal enterotoxin B (SEB, $10 \%$ ). It was reported that a dose of about $40 \mathrm{ng}$ of SEA or SED is sufficient to induce intoxication (3). Therefore, to ensure the safety of raw milk cheese, growth of S. aureus must be controlled. In 2006, the European legislation laid down the obligation to determine the presence of enterotoxins in cheese when the level of $S$. aureus is over $5 \log \mathrm{CFU} / \mathrm{g}(21)$. Thus, it is very important to investigate bacterial interactions to understand the mechanisms by which the inhibition of pathogens by other bacterial species may occur. It is well documented that some lactic acid bacteria (LAB) are able to inhibit $S$. aureus growth $(22,23)$ mainly by production of organic acids (lactic acid). Both decreasing $\mathrm{pH}$ (acidification) and increasing undissociated lactic acid concentration have been reported to exert the inhibitory effects on pathogens. To the best of our knowledge, there are few reports on the inhibition of SEA production especially by LAB. The manufacturers of raw milk cheese rely on the biopreservative action of the sole autochthonous flora of the used milk or on the addition of selected strains with antimicrobial potential. Therefore, the main aims of this study are the manufacture of fresh raw milk cheese by applying a selected anti-staphylococcal Lactococcus lactis strain and the evaluation of its inhibitory effect on Staphylococcus aureus growth and SEA production.

\section{Materials and Methods}

\section{Lactococcus lactis identification and growth conditions}

A strain of L. lactis, originally isolated from raw milk, collected from a healthy cow in Bejaia city (Algeria), and selected on the basis of its strongest anti-Staphylococcus activity, was used in this study. It was cultivated in M17 broth and agar (Difco, Le Pont de Claix, France) at $30{ }^{\circ} \mathrm{C}$. This strain was identified by $16 \mathrm{~S}$ rDNA sequencing. Briefly, genomic DNA was extracted using Qiagen kit (Qiagen, Hilden, Germany) as follows. A volume of $2 \mathrm{~mL}$ of an overnight culture of the strain was centrifuged at $5000 \times g$ (Sigma 1-14; Sigma Zentrifugen, Osterode am Harz, Germany) for $10 \mathrm{~min}$ and the supernatant was discarded. The pellet was then suspended in $180 \mu \mathrm{L}$ of enzymatic lysis buffer (Qiagen). The extraction was continued following the manufacturer's instructions. 16S rRNA gene was amplified by polymerase chain reaction (24) using universal primers (Qiagen) (Table 1).
Table 1. Oligonucleotide primers used for Staphylococcus aureus and Lactococcus lactis identification

\begin{tabular}{ccc}
\hline Strain & Primer & Sequence \\
\hline \multirow{2}{*}{ S. aureus } & OlF515 & 5' GTGCCAGC(AC) GCCGCGG 3' \\
& OlF915 & 5' A(GT) GAATTGACGGGG(AG) C 3’ \\
& & \\
L. lactis & OlR1406 & 5' ACGGGCGGTGTGT(AG) C 3' \\
& OlR930 & 5' G(CT) CCCCGTCAATTC(AC) T 3' \\
\hline
\end{tabular}

\section{Staphylococcus aureus isolation, identification and growth conditions}

Raw milk samples for S. aureus isolation were collected from cows with subclinical mastitis in different farms located in Bejaia city (Algeria). Milk samples were collected aseptically into sterile $250-\mathrm{mL}$ bottles after disinfection of the mammary udders. Before isolation, enrichment for staphylococcal growth was carried out in Giolitti-Cantoni broth (GC; Pasteur Institute of Algeria, Algiers, Algeria) supplemented with $1 \%$ (by volume) potassium tellurite (Pasteur Institute of Algeria) and incubated at $37^{\circ} \mathrm{C}$ for $24 \mathrm{~h}$ under anaerobic conditions. Isolation was carried out on mannitol salt agar $\left(\right.$ Bacto $^{\mathrm{TM}}$, Le Pont de Claix, France) and plates were incubated at $37{ }^{\circ} \mathrm{C}$ for 24 $-48 \mathrm{~h}$ under aerobic conditions. Characteristic colonies were identified phenotypically as previously described (25) using Gram staining, catalase, coagulase and DNase tests. The selected strains were identified by $16 \mathrm{~S}$ rRNA gene sequencing. Genomic DNA was extracted using Qiagen kit. 16S rRNA gene was amplified by polymerase chain reaction (24) using universal primers (Qiagen) (Table 1). Strains were stored on nutrient agar (NA; Sigma-Aldrich Chemie, Steinheim, Germany) at $4{ }^{\circ} \mathrm{C}$ until use. For long-term storage, the strains were stored in brain heart infusion broth (BHI; Sigma-Aldrich Chemie) supplemented with 30 $\%$ (by volume) glycerol (Sigma-Aldrich Chemie) at $-20^{\circ} \mathrm{C}$.

\section{In vitro anti-staphylococcal activity of L. lactis}

Agar diffusion methods

L. lactis antibacterial activity against $S$. aureus was detected using the spot-on-lawn and the well diffusion methods (26). Briefly, L. lactis was cultured overnight in M17 broth (Difco) at $30^{\circ} \mathrm{C}$. An aliquot $(5 \mu \mathrm{L})$ of $L$. lactis culture was spotted onto M17 agar and incubated at $30^{\circ} \mathrm{C}$ for $18 \mathrm{~h}$. Then the plates were overlaid with $10 \mathrm{~mL}$ of Müller-Hinton agar (MH; Pasteur Institute of Algeria) inoculated with the S. aureus strain at a final concentration of $5 \log \mathrm{CFU} / \mathrm{mL}$ and re-incubated at $37^{\circ} \mathrm{C}$ for $24 \mathrm{~h}$. Finally, appearance of the inhibition zone around the spots was observed. For well diffusion method, L. lactis cell-free supernatant (CFS) was recovered from an overnight culture $(9 \log \mathrm{CFU} / \mathrm{mL})$ centrifuged at $8000 \times g$ for $20 \mathrm{~min}$ at $4{ }^{\circ} \mathrm{C}$ (Sorvall RC-5C Plus, Thermo Fisher Scientific, Bad Homburg, Germany) and then filter-sterilized through $0.22-\mu \mathrm{m}$ Millipore filters (Merck Millipore, St. Quentin en-Yvelines Cedex, France). MH agar plates were inoculated with $S$. aureus $(5 \log \mathrm{CFU} / \mathrm{mL})$ and cooled at $4{ }^{\circ} \mathrm{C}$ for $30 \mathrm{~min}$, then wells $(6 \mathrm{~mm}$ in diameter) were made and filled with $L$. lactis CFS $(100 \mu \mathrm{L})$. To allow 
diffusion of the tested supernatant, the plates were pre-incubated at $4{ }^{\circ} \mathrm{C}$ for $2 \mathrm{~h}$. At the end of the incubation period $\left(37^{\circ} \mathrm{C}\right.$ for $\left.18 \mathrm{~h}\right)$, the anti-staphylococcal activity was estimated by measuring the inhibition zone diameters. Neutralized CFS ( $\mathrm{pH}=6.5,3 \mathrm{~mol} / \mathrm{L}$ of $\mathrm{NaOH}$ ) was also tested using the same method.

\section{Co-cultures in M17 broth and milk}

In this test, the study of the in vitro antagonism of the lactococcal strain against $S$. aureus was performed by co-culture in M17 broth or skimmed milk to assess the inhibitory potential of $L$. lactis strain when it coexists with $S$. aureus. The latter was cultivated in $9 \mathrm{~mL}$ of M17 broth or skimmed milk at $37^{\circ} \mathrm{C}$ overnight. After incubation, it was inoculated into $100 \mathrm{~mL}$ of the same medium to have a final count of $6 \log \mathrm{CFU} / \mathrm{mL}$ (the highest level of $S$. aureus enumerated in the mastitic raw milk samples used for isolation of the $S$. aureus strain) in 250-mL glass flasks. Like S. aureus, L. lactis was pre-cultured in $9 \mathrm{~mL}$ of M17 broth or skimmed milk at $30{ }^{\circ} \mathrm{C}$ overnight, and then inoculated into $100 \mathrm{~mL}$ of the same medium (final level of $8 \log \mathrm{CFU} / \mathrm{mL}$, the mean count of lactic acid bacteria, including lactococci, enumerated in our raw milk samples), previously inoculated with $S$. aureus as described above. Similarly, pure cultures of $L$. lactis and $S$. aureus were prepared in the same media and at the same final cell levels. Pure and co-cultures were incubated at $30^{\circ} \mathrm{C}$ under aerobic static conditions. Culture aliquots $(10 \mathrm{~mL})$ were periodically sampled for $S$. aureus viable cell enumeration on mannitol salt agar (Bacto ${ }^{\mathrm{TM}}$ ), $\mathrm{pH}$ determination (universal $\mathrm{pH}$ indicator paper, $\mathrm{pH}=1-14$; Merck KGaA, Gernsheim, Germany) and SEA detection (in M17 broth). Similarly, growth of L. lactis in pure cultures was followed at the same time intervals. The measurements were carried out at $0,2,4,6,8,10,12$ and $24 \mathrm{~h}$ of incubation in three independent experiments.

\section{Enzyme-linked immunosorbent assay (ELISA) test for SEA detection and quantification}

Staphylococcal enterotoxin A (SEA) was detected in the CFS obtained from $S$. aureus pure and co-cultures in M17. CFS was recovered as indicated above and stored at $4{ }^{\circ} \mathrm{C}$ until analyses. SEA was first detected in CFS obtained from a 24-hour culture, then quantified in CFS obtained after each incubation period $(2,4,6,8,10$ and $12 \mathrm{~h}$ ) from $S$. aureus pure and co-cultures (with L. lactis) using ELISA test. This test was performed in 96-well polystyrene plates (Greiner Bio One, Frickenhausen, Germany). The protocol was as follows: first, the polystyrene plate wells were coated overnight at $4{ }^{\circ} \mathrm{C}$ with $100 \mu \mathrm{L}$ of CFS and pure SEA (Sigma-Aldrich, St. Louis, USA) at concentrations from 5 to $100 \mathrm{ng} / \mathrm{mL}$ (with an increment factor of 5 ) as positive controls. Second, the plates were saturated with $150 \mu \mathrm{L}$ of phosphate buffered saline-bovine serum albumin (PBS-BSA) $1 \%$ (by mass per volume) for $1 \mathrm{~h}$ at room temperature. Third, $100 \mu \mathrm{L}$ of diluted (1:500 in $1 \%$ (by mass per volume) PBS-BSA) rabbit anti-SEA antibody (Sigma-Aldrich) were added to each well. The plates were incubated at $37^{\circ} \mathrm{C}$ for $2 \mathrm{~h}$ and then washed three times with PBS containing $0.1 \%$ (by volume) Tween 20 (Sigma-Aldrich). Forth, the secondary antibody: $100 \mu \mathrm{L}$ of dilut- ed (1:1000) anti-rabbit immunoglobulin G (whole molecule) alkaline-phosphatase-conjugate antibody developed in goat's serum (Sigma-Aldrich) were added to each well and the plates were left for $1 \mathrm{~h}$ at room temperature. Finally, for colorimetric detection, $100 \mu \mathrm{L}$ of the phosphatase substrate, $p$-nitrophenylphosphate at $1 \mathrm{mg} / \mathrm{mL}$ in diethanolamine buffer $\mathrm{pH}=9.6$ (Sigma-Aldrich), were added per well. The absorbance was read at $405 \mathrm{~nm}$ with an automatic ELISA plate reader (Power WaveX 340; Bio-Tek Instruments, Inc., Winooski, VT, USA) after $30 \mathrm{~min}$ at room temperature. In the same step, to quantify the amount of SEA in CFS and obtain SEA standard curve, pure SEA solutions at increasing concentrations $(0.75-100 \mathrm{ng} / \mathrm{mL})$ were incubated separately. The amount of SEA $(\mathrm{ng} / \mathrm{mL})$ in CFS was determined from the standard curve.

\section{In situ anti-staphylococcal activity of L. lactis}

\section{Cheese manufacturing}

Cheese samples were made from raw cow's milk. Before cheese making, the presence of $S$. aureus in raw milk was assessed. Milk at $30{ }^{\circ} \mathrm{C}(\mathrm{pH}=6.5)$ was divided equally in three 2-litre vats; the first one was inoculated with $S$. aureus solely ( $3 \log \mathrm{CFU} / \mathrm{mL}$, the mean level of $S$. aureus enumerated from naturally contaminated raw milk), whereas the second vat was inoculated simultaneously with $S$. aureus $(3 \log \mathrm{CFU} / \mathrm{mL})$ and L. lactis $(8 \log \mathrm{CFU} /$ $\mathrm{mL}$ ). A non-inoculated vat was included as a control to assess any $S$. aureus contamination during the cheese making. Rennet (Caglificio Clerici Spa., Cadorago, Italy) was added to milk $(1.5 \mu \mathrm{g} / \mathrm{L})$ one hour after the culture inoculation. Forty minutes after rennet addition, the curd was cut and whey was drained off. The obtained curd was distributed into cylindrical perforated stainless steel moulds and left for $6 \mathrm{~h}$ at room temperature, then immersed in 20 $\%$ (by mass per volume) brine for $30 \mathrm{~min}$, and maintained for $2 \mathrm{~h}$ at room temperature. Finally, the cheese samples were stored at $8{ }^{\circ} \mathrm{C}$ for 32 days.

\section{Staphylococcus aureus count in cheese}

Viable cells of $S$. aureus in cheese were counted every day during the first week of storage and then on days 14, 21, 28 and 32. Cheese samples (5 g) were homogenized in $45 \mathrm{~mL}$ of sterile saline water $(9 \mathrm{~g} / \mathrm{L} \mathrm{NaCl})$ at $45^{\circ} \mathrm{C}$ and then serial decimal dilutions were carried out and plated in triplicate on mannitol salt agar $\left(\right.$ Bacto $\left.^{\mathrm{TM}}\right)$. After incubation (at $37^{\circ} \mathrm{C}$ for $48 \mathrm{~h}$ ), the $S$. aureus number was determined and expressed in CFU per g of cheese.

\section{SEA extraction and detection in cheese}

Staphylococcal enterotoxin A was extracted following the procedure of Soejima et al. (27) and detected using Western blot test with some modifications. Briefly, $20 \mathrm{~g}$ of cheese were combined with $40 \mathrm{~mL}$ of distilled water $\left(37^{\circ} \mathrm{C}\right)$ and homogenized. The suspension was adjusted to $\mathrm{pH}=3.8-4$ with $2 \mathrm{~mol} / \mathrm{L}$ of $\mathrm{HCl}$ (Sigma-Aldrich) and left for $10 \mathrm{~min}$ at room temperature, then centrifuged at $3000 \times g$ (Sigma 1-14; Sigma Zentrifugen) for 20 min at $4{ }^{\circ} \mathrm{C}$. The supernatant was adjusted to $\mathrm{pH}=6.6$ -6.8 with $2 \mathrm{~mol} / \mathrm{L}$ of $\mathrm{NaOH}$ (Sigma-Aldrich). Chloroform (Sigma-Aldrich) was added to the supernatant at a 
final volume fraction of $10 \%$; the mixture was vigorously shaken for $20 \mathrm{~s}$ and then centrifuged at $3000 \times g$ (Sigma 1-14; Sigma Zentrifugen) for $20 \mathrm{~min}$ at $4{ }^{\circ} \mathrm{C}$. Cold trichloroacetic acid (Sigma-Aldrich) was added at a final mass per volume ratio of $20 \%$ to the obtained supernatant. After cooling on ice for $30 \mathrm{~min}$, the mixture was centrifuged again $\left(3000 \times g\right.$ for $30 \mathrm{~min}$ at $\left.4{ }^{\circ} \mathrm{C}\right)$, the pellet was resuspended in Tris (Sigma-Aldrich) buffer $(0.3 \mathrm{M}$, $\mathrm{pH}=8)$ and then stored at $-20{ }^{\circ} \mathrm{C}$ until analyses. Western immunoblot analysis was done with the polyclonal antiserum prepared against SEA. Samples were electrophoresed through a $12 \%$ (by mass per volume) sodium dodecyl sulfate polyacrylamide gel with a $6 \%$ (by mass per volume) stacking gel (28) and electrophoretically transferred to nitrocellulose membrane (Whatman ${ }^{\circledR}$ Protran $^{\circledR}$; Sigma-Aldrich, Dassel, Germany). Cheese extracts were boiled for 10 min just before being loaded onto the $12 \%$ SDS-PAGE gel. Protein molecular mass standards (Euromedex, Souffelweyersheim, France) were also loaded onto the gel. The Bio-Rad mini gel (1.5) apparatus (Bio-Rad, Marnes-la-Coquette, France), used for SDS-PAGE, was run for $1 \mathrm{~h}$ at $180 \mathrm{~V}$, and then the gels were transferred to the nitrocellulose membrane at $100 \mathrm{~V}$ for $1 \mathrm{~h}$. The membrane was blocked with $5 \%$ Tris-buffered saline-bovine serum albumin (TBS-BSA; Thermo Scientific $^{\mathrm{TM}}$, Thermo Fisher Scientific, Inc., Waltham, NA, USA) for $1 \mathrm{~h}$, incubated with rabbit anti-SEA antibody (Sigma-Aldrich) and raised against native SEA, diluted at 1:500 (by volume) in TBS-BSA for $1 \mathrm{~h}$. After washing, the membrane was incubated with an anti-rabbit horseradish peroxidase (HRP; Jackson ImmunoResearch, West Grove, PA, USA) diluted at 1:1000 (by volume) in TBSBSA for $1 \mathrm{~h}$. Following a second washing, the mixture of HRP substrate SuperSignal West Pico Stable Peroxide/SuperSignal West Pico Luminol/Enhancer solution (Thermo Scientific ${ }^{\mathrm{TM}}$, Thermo Fisher Scientific, Inc.) was added and the Western blots were scanned using a Fluor Chem Q (Cell Biosciences, Santa Clara, CA, USA) apparatus.

\section{Statistical analysis}

All the experiments were performed in triplicate and results were expressed as mean value \pm standard deviation. Statistical analysis was performed using one-way analysis of variance (ANOVA) together with the Tukey's test using the STATISTICA v. 10 (StatSoft, Paris, France) software. Values of $\mathrm{p}<0.05$ were considered significant.

\section{Results and Discussion}

\section{Lactococcus lactis exerts a significant anti- staphylococcal activity in vitro}

Lactococcus lactis was found to possess an antibacterial activity against Staphylococcus aureus following the spot-on-lawn and the well diffusion tests with inhibition zone diameters of 17 (Fig. 1) and $10 \mathrm{~mm}$ (not shown), respectively. However, these inhibition zones disappeared when testing the neutralized cell-free supernatant (CFS), which indicates the effect of acidic $\mathrm{pH}$ on the antibacterial activity.

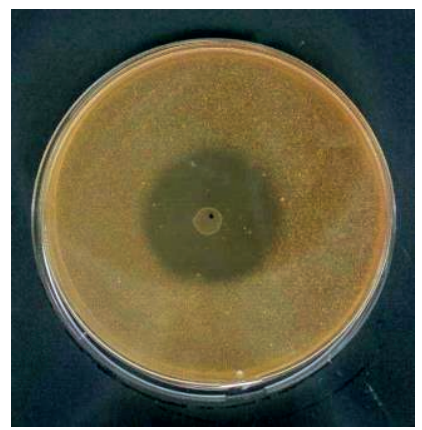

Fig. 1. Anti-staphylococcal activity of Lactococcus lactis strain (inhibition zone diameter of $17 \mathrm{~mm}$ ) following the spot-on-lawn test

This activity was also demonstrated in M17 broth (Fig. 2) and milk co-cultures (Fig. 3). S. aureus growth in M17 broth (pure cultures) was biphasic; it was exponential until $12 \mathrm{~h}$ of incubation with a population reaching approx. 9.1 $\log \mathrm{CFU} / \mathrm{mL}$, then stationary with stable cell number during the 24-hour culture period (approx. $9.1 \log \mathrm{CFU} /$ $\mathrm{mL}$; Fig. 2a). In the co-cultures with L. lactis, S. aureus growth was similar to that observed in the pure cultures during the first four hours of incubation, with a population level of $7.4 \log C F U / m L$ in both cultures. However, after $6 \mathrm{~h}$ of incubation, a significant decrease $(\mathrm{p}<0.05)$ in the $S$. aureus viable cell number was registered and it reached $6 \log$ CFU/mL at the end of the growth period $(24 \mathrm{~h})$, with $3-\log$ reduction compared to the pure cultures (Fig. 2a).

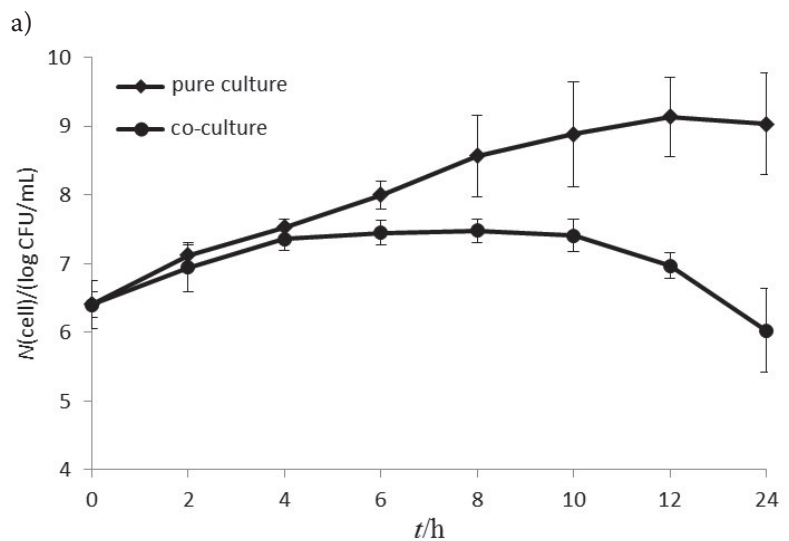

b)

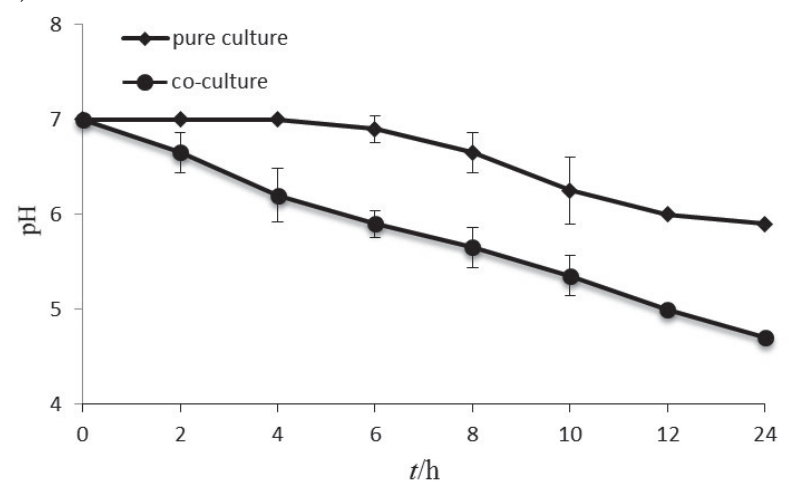

Fig. 2. Growth kinetics of Staphylococcus aureus (a) and pH evolution (b) in pure and co-cultures in M17 broth. Values are the average of three independent experiments. Error bars correspond to standard deviations 


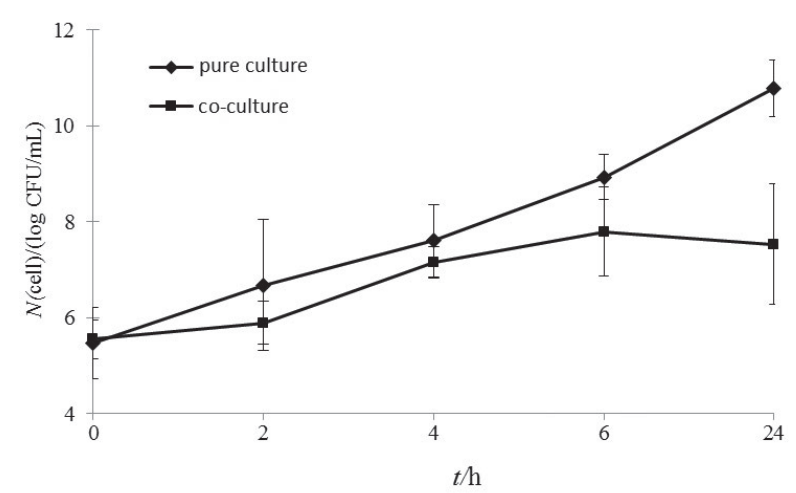

Fig. 3. Growth kinetics of Staphylococcus aureus in pure and co-cultures in skimmed milk at $30{ }^{\circ} \mathrm{C}$. Values are the average of three independent experiments. Error bars correspond to standard deviations

This inhibitory effect was concomitant to a significant $\mathrm{pH}$ drop in the co-cultures. Indeed, $\mathrm{pH}$ evolution during pure and co-cultures in M17 broth was determined every $2 \mathrm{~h}$ (Fig. 2b). The $\mathrm{pH}$ value decreased in the $S$. aureus pure cultures by only one unit (from $\mathrm{pH}=7$ to $\mathrm{pH}=6$ ) after $24 \mathrm{~h}$ of incubation. On the contrary, in the co-cultures with $L$. lactis $(8 \log \mathrm{CFU} / \mathrm{mL})$ the $\mathrm{pH}$ was much lower $(\mathrm{pH}=4.9)$ at the end of the culture period ( $24 \mathrm{~h}$; Fig. $2 \mathrm{~b}$ ). This decrease in the $\mathrm{pH}$ value in the co-cultures may be explained by the glucose metabolisms of both strains. According to the classification established by Charlier et al. (29) based on $S$. aureus population and $\mathrm{pH}$ value reductions, our $L$. lactis strain could be classified in group II (with low acidification and strong inhibition potential). Therefore, L. lactis seemed to exert a good inhibitory effect on the $S$. aureus growth; acidification and accumulation of undissociated lactic acid form may be the main plausible mechanisms involved in this effect. Similarly, when cultured in skimmed milk with L. lactis (Fig. 3), S. aureus viable cells reached a count of 7.14 $\log \mathrm{CFU} / \mathrm{mL}$ after $4 \mathrm{~h}$ of incubation. This count remained stable throughout the culture, contrary to the pure cultures where S. aureus average level was $10.78 \log$ CFU/mL after $24 \mathrm{~h}$ of incubation. This difference may be due to the inhibitory activity of L. lactis as observed in M17 broth.

The antibacterial activity of L. lactis is well documented in the literature and many strains have been recognized for their anti-staphylococcal action (29-32). Similar results were reported by Even et al. (33) and Samelis et al. (34), and inhibition of $S$. aureus growth in milk was already reported by Muñoz et al. (6), Charlier et al. (35) and Le Marc et al. (36). Some studies have shown that co-culture with lactic acid bacteria reduced $S$. aureus growth following nutritional competition. Indeed, these bacteria (including L. lactis) are able to metabolize different carbon sources, such as glucose and lactose, which are also used by $S$. aureus (29). Furthermore, competition for vital nutritive elements, such as biotin and niacin, was shown to be responsible for the $S$. aureus inhibition in co-cultures with L lactis (29). This anti-staphylococcal effect may also be due to specific substances produced by L. lactis, mainly organic acids, leading to medium acidification $(35,36)$.

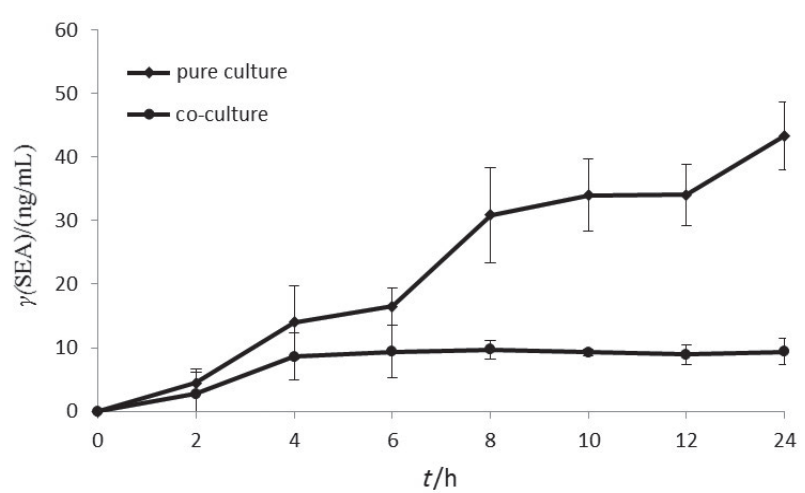

Fig. 4. Staphylococcal enterotoxin A (SEA) production at $37{ }^{\circ} \mathrm{C}$ in pure and co-cultures in M17 broth as detected by ELISA test in the supernatants. Values are the average of three independent experiments. Error bars correspond to standard deviations

\section{Inhibition of SEA production by Lactococcus lactis}

Parallel with the growth monitoring, SEA production was followed in M17 broth pure and co-cultures, and it was quantified using ELISA test. SEA was detected in the CFS after $2 \mathrm{~h}$ of incubation (Fig. 4). Derzelle et al. (37) have reported that SEA can be produced during all $S$. aureus growth phases. Similarly, Rasooly and Rasooly (38) demonstrated that SEA was produced after $160 \mathrm{~min}$ of culture in BHI broth. In pure S. aureus cultures, SEA production increased progressively and reached 30.83 and $34.05 \mathrm{ng} / \mathrm{mL}$ after 8 and $12 \mathrm{~h}$ of incubation, respectively. After $24 \mathrm{~h}$ of incubation, toxin concentration was about $43.5 \mathrm{ng} / \mathrm{mL}$. However, in the co-cultures with L. lactis, SEA level was significantly $(\mathrm{p}<0.05)$ lower than that determined in the pure cultures. It was lower than $10 \mathrm{ng} / \mathrm{mL}$ throughout the incubation period $(24 \mathrm{~h})$. In these cultures, SEA level was reduced by $79 \%(<10 \mathrm{ng} / \mathrm{mL})$, which demonstrates that toxin production was inhibited by L. lactis. Even et al. (33) have reported that changes in the expression of enterotoxins A and L genes (sea and sel) occurred in co-cultures of $S$. aureus with L. lactis ssp. lactis biovar. diacetylactis LD61 in a chemically defined medium. Furthermore, Rosengren et al. (39) have demonstrated that accumulation of undissociated lactic acid exerts a significant inhibitory effect on SEA production. This could explain our results since the $\mathrm{pH}$ decreased to $\mathrm{pH}=4.9$ in the presence of L. lactis strain (Fig. 2b).

\section{Inhibition of S. aureus growth and SEA production in cheese}

To investigate the anti-staphylococcal activity of the lactococcal strain in situ, the latter was applied to manufacture a fresh cheese using raw milk experimentally contaminated with $S$. aureus. For this, raw milk was firstly analyzed for $S$. aureus presence and no cell was detected. The milk was then inoculated with $3 \log \mathrm{CFU} / \mathrm{mL}$ of $S$. aureus and its growth was monitored. A maximum of 5.39 $\log$ CFU of $S$. aureus per $g$ of cheese was reached after one day of cheese manufacture, but this level was maintained at the initial level $(3 \log \mathrm{CFU} / \mathrm{mL})$ in the cheese made with the addition of L. lactis (Fig. 5). This different behaviour was observed throughout the first week after inoculation; 


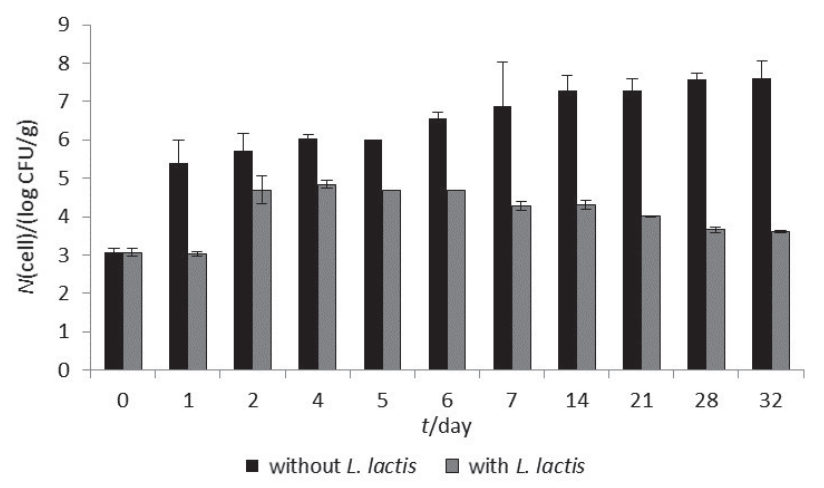

Fig. 5. Staphylococcus aureus strain counts in cheese manufactured without and with Lactococcus lactis strain and stored at $6{ }^{\circ} \mathrm{C}$ for 32 days. Values are the average of two independent experiments. Error bars correspond to standard deviations

indeed, S. aureus counts increased progressively in the two types of cheese but obtained 6.87 and $4.3 \mathrm{log}$ CFU/g respectively at the end of this storage period. Similarly, on the 32nd day of storage, $S$. aureus cell number in cheese made with L. lactis (3.6 log CFU/g) was significantly $(\mathrm{p}<0.05)$ lower $(4 \log$ units) than that recorded in cheese containing only the pathogen bacterium (7.6 log CFU/g). Therefore, cheese manufactured with L. lactis was significantly $(\mathrm{p}<0.05)$ less populated with $S$. aureus than the cheese made without this lactic strain. According to these results, the lactic strain used in this study was highly effective in controlling $S$. aureus growth in cheese. This effectiveness was well highlighted by the significant decrease of the viable $S$. aureus counts from the beginning until the end of the storage period (32 days). As mentioned in Materials and Methods, a control cheese made with non-inoculated raw milk was included in this trial and non-S. aureus cells were detected during the manufacture and throughout the storage period. Parallel with $S$. aureus cell count monitoring, SEA production was inspected in cheese extracts using the Western blot system. It was detected after 21 days of storage in the extracts of cheese made without $L$. lactis and remained detectable until the end of storage (Fig. 6). This observation is in agreement with the staphylococcal count evolution in the cheese. During this period, the number of viable staphylococcal cells was around $7 \mathrm{log} \mathrm{CFU} / \mathrm{g}$. According to Fujikawa and Morozumi (40), SEA could be detected when $S$. aureus population was over $6 \log \mathrm{CFU} / \mathrm{mL}$. Conversely, extracts from cheese made with $L$. lactis were devoid of SEA. It was never detected during storage period since $S$. aureus was below the permitted SEA detection level ( $<6$ log CFU/g). This result may be related to the antibacterial activity of the lactic strain against $S$. aureus growth and SEA production, also exerted in cheese. It was reported that in artisanal cheese, L. lactis was a predominant flora with a good acidification and an ability to produce antimicrobial compounds (41). However, in the study of Hamama et al. (42), when $S$. aureus was present at high levels (>5 $\log \mathrm{CFU} / \mathrm{mL}$ ) in the milk, staphylococcal enterotoxins were rapidly formed in the cheese, even in the presence of a nisin-producing lactic starter. Consequently, raw milk quality and good conditions of manufacture are primordial to insure cheese safety. This study emphasized

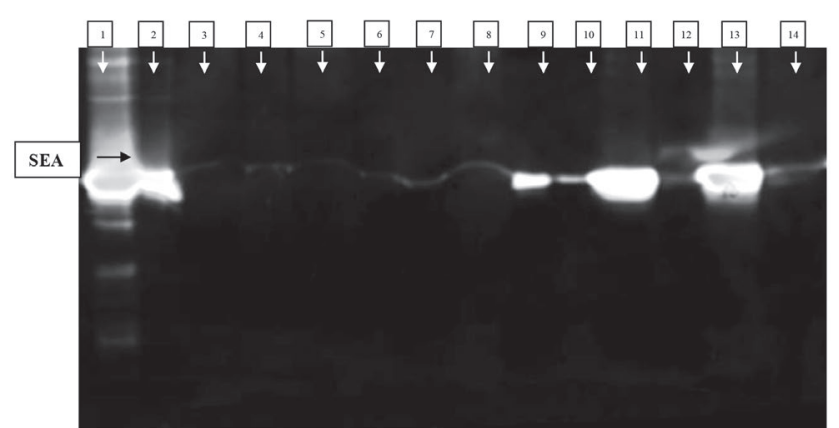

Fig. 6. Staphylococcal enterotoxin A (SEA) detection in cheese extracts by the Western blot analysis following storage at $8{ }^{\circ} \mathrm{C}$ for 32 days. lane $1=$ molecular mass ladder, lane $2=\gamma\left(\mathrm{SEA}_{\text {pure }}\right)=50 \mathrm{ng} / \mu \mathrm{L}$, lanes 3, 5, 7, 9, 11 and 13 =extracts from cheese made with only $S$. aureus at $0,7,14,21,28$ and 32 days of storage, respectively, lanes 4 , 6, 8, 10, 12 and 14=extracts from cheese made with $S$. aureus and $L$. lactis at $0,7,14,21,28$ and 32 days of storage, respectively

the importance of maintaining the $S$. aureus counts in milk at less than $3 \log \mathrm{CFU} / \mathrm{mL}$. The active growth of $S$. aureus in cheese (in the absence of L. lactis) during storage indicates the possibility of a public health hazard, despite the low contamination level of milk, and so implicates the presence of staphylococcal enterotoxins in raw milk cheese. On the contrary, in cheese made with L. lactis, S. aureus growth was drastically inhibited, and this pathogen did not attain a population level that would allow SEA production. It was at a level lower than $5 \mathrm{log}$ CFU/g during the entire storage period.

\section{Conclusions}

Lactococci (Lactococcus lactis) are largely used as industrial or artisanal starter cultures for the manufacture of many cheese types, including fresh and soft cheese. To our knowledge, this is the first report where L. lactis, the model LAB, isolated from Algerian cow's milk, has been shown to have a drastic inhibitory effect on $S$. aureus growth and staphylococcal enterotoxin A (SEA) production in cheese. This inhibition was demonstrated in a laboratory medium and in milk where $S$. aureus growth was significantly reduced in co-culture with $L$. lactis strain. Consequently, SEA production was also decreased. The lactic strain studied in this work was found to effectively inhibit $S$. aureus growth and SEA production during raw milk cheese storage (32 days). As shown in this study, L. lactis strain is capable of preventing S. aureus growth and subsequent enterotoxin A production in cheese, particularly when the initial milk contamination with $S$. aureus is lower than $3 \log \mathrm{CFU} / \mathrm{mL}$. This finding confirmed the great importance of the use of this lactic strain in cheese making and preservation.

\section{Acknowledgements}

The authors are grateful to the Algerian Ministry of Higher Education and Scientific Research for the financial support. They also thank Dr. Ange Pujol for his technical assistance and Dr. Marius Reglier and Michel Fons for their help during this work. 


\section{References}

1. Le Loir Y, Baron F, Gautier M. Staphylococcus aureus and food poisoning. Genet Mol Res. 2003;2:63-76.

2. Murray RJ. Recognition and management of Staphylococcus aureus toxin-mediated disease. Int Med J. 2005;35:S106-19. https://doi.org/10.1111/j.1444-0903.2005.00984.x

3. Ikeda T, Tamate N, Yamaguchi K, Makino S. Mass outbreak of food poisoning disease caused by small amount of staphylococcal enterotoxins A and H. Appl Environ Microbiol. 2005;71:2793-5. https://doi.org/10.1128/AEM.71.5.2793-2795.2005

4. Boufaida Asnoune Z, Butel MJ, Ouzrout R. Prevalence of major bacteria causing subclinical mastitis in dairy cows in northeastern Algeria. Rev Elev Med Vet Pays Trop. 2012;65:5-9 (in French). https://doi.org/10.19182/remvt.10132

5. Bouaziz O, Aïmeur R, Kabouia R, Bererhi EH, Smati F, Tainturier D. Prevalence of the different germs responsible for clinical mastitis of cows in eastern Algeria. Sci Technol. 2002;DZ27-32 (in French).

6. Muñoz A, Ananou S, Gàlvezc A, Martínez-Bueno M, Rodríguez AM, Maqueda M, Valdivia E. Inhibition of Staphylococcus aureus in dairy products by enterocin AS-48 produced in situ and ex situ: Bactericidal synergism with heat. Int Dairy J. 2007;17:7609.

https://doi.org/10.1016/j.idairyj.2006.09.006

7. Frece J, Vrdoljak M, Filipčić M, Jelić M, Čanak I, Jakopović Ž, et al. Microbiological quality and variability of natural microbiota in Croatian cheese maturing in lambskin sacks. Food Technol Biotechnol. 2016;54:129-34.

https://doi.org/10.17113/ftb.2016.54.02.16.4418

8. Salgado-Ruiz TB, Rodríguez A, Gutiérrez D, Martínez B, García P, Espinoza-Ortega A, et al. Molecular characterization and antimicrobial susceptibility of Staphylococcus aureus from smallscale dairy systems in the highlands of Central Mexico. Dairy Sci Technol. 2015;95:181-96.

https://doi.org/10.1007/s13594-014-0195-0

9. Jahid IK, Ha SD. A review of microbial biofilms of produce: Future challenge to food safety. Food Sci Biotechnol. 2012;21:299_ 316. https://doi.org/10.1007/s10068-012-0041-1

10. Sommerhäuser J, Kloppert B, Wolter W, Zschöck M, Sobiraj A, Failing K. The epidemiology of Staphylococcus aureus infections from subclinical mastitis in dairy cows during a control programme. Vet Microbiol. 2003;96:91-102.

https://doi.org/10.1016/S0378-1135(03)00204-9

11. Meyrand A, Boutrand-Loei S, Ray-Gueniot S, Mazuy C, Gaspard $\mathrm{CE}$, Jaubert G, et al. Growth and enterotoxin production of Staphylococcus aureus during the manufacture and ripening of Camembert-type cheeses from raw goat milk. J Appl Microbiol. 1998;85:537-44. https://doi.org/10.1046/j.1365-2672.1998.853531.x

12. Cenci-Goga BT, Karama M, Rossitto PV, Morgante RA, Cullor JS. Enterotoxin production by Staphylococcus aureus isolated from mastitic cows. J Food Prot. 2003;66:1693-96. https://doi.org/10.4315/0362.028X-66.9.1693

13. Martins IM, Kabuki DY, Nago Miya NT, Pereira JL. Occurrence and characterization of enterotoxingenic potential of Staphylococcus isolated from dairy products. J Food Safety. 2014;34:18592. https://doi.org/10.1111/jfs.12112

14. Balaban N, Rasooly A. Staphylococcal enterotoxins. Int J Food Microbiol. 2000;61: 1-10. https://doi.org/10.1016/S0168-1605(00)00377-9

15. Hu DL, Nakane A. Mechanisms of staphylococcal enterotoxin-induced emesis. Eur J Pharmacol. 2014;722:95-107. https://doi.org/10.1016/j.ejphar.2013.08.050

16. Jørgensen HJ, Mørk T, Caugant DA, Kearns A, Rørvik LM. Genetic variation among Staphylococcus aureus strains from Nor- wegian bulk milk. Appl Environ Microbiol. 2005;71:8352-61. https://doi.org/10.1128/AEM.71.12.8352-8361.2005

17. Thomas DY, Jarraud S, Lemercier B, Cozon G, Echasserieau K, Etienne J, et al. Staphylococcal enterotoxin-like toxins U2 and V, two new staphylococcal superantigens arising from recombination within the enterotoxin gene cluster. Infect Immun. 2006;74:4724-34. https://doi.org/10.1128/IAI.00132-06

18. Argudín MA, Mendoza MC, Rodicio MR. Food poisoning and Staphylococcus aureus enterotoxins. Toxins. 2010;2:1751-73. https://doi.org/10.3390/toxins2071751

19. Jørgensen HJ, Mørk T, Rørvik LM. The occurrence of Staphylococcus aureus on a farm with small-scale production of raw milk cheese. J Dairy Sci. 2005;88:3810-17. https://doi.org/10.3168/jds.S0022-0302(05)73066-6

20. Normanno G, Firinu A, Virgilio S, Mula G, Dambrosio A, Poggiu A, et al. Coagulase-positive staphylococci and Staphylococcus aureus in food products marketed in Italy. Int J Food Microbiol. 2005;98:73-9. https://doi.org/10.1016/j.ijfoodmicro.2004.05.008

21. Cremonesi P, Perez G, Pisoni G, Moroni P, Morandi S, Luzzana $\mathrm{M}$, et al. Detection of enterotoxigenic Staphylococcus aureus isolates in raw milk cheese. Lett Appl Microbiol. 2007;45:58691. https://doi.org/10.1111/j.1472-765X.2007.02231

22. Topisirovic Lj, Kojic M, Fira D, Golic N, Strahinic I, Lozo J. Potential of lactic acid bacteria isolated from specific natural niches in food production and preservation. Int J Food Microbiol. 2006;112:230-5.

https://doi.org/10.1016/j.ijfoodmicro.2006.04.009

23. Gyu Dimitrieva-Moats, Ünlü G. Development of freeze-dried bacteriocin-containing preparations from lactic acid bacteria to inhibit Listeria monocytogenes and Staphylococcus aureus. Probiotics Antimicrob Proteins. 2012;4:27-38. https://doi.org/10.1007/s12602-011-9088-1

24. Marcille F, Gomez A, Joubert P, Ladiré M, Veau G, Clara A, et al. Distribution of genes encoding the trypsin-dependent lantibiotic ruminococcin A among bacteria isolated from human fecal microbiota. Appl Environ Microbiol. 2002;68:3424-31. https://doi.org/10.1128/AEM.68.7.3424-3431.2002

25. Boynukara B, Gulhan T, Alisarli M, Gurturk K, Solmaz H. Classical enterotoxigenic characteristics of Staphylococcus aureus strains isolated from bovine subclinical mastitis in Van, Turkey. Int J Food Microbiol. 2008;125:209-11. https://doi.org/10.1016/j.ijfoodmicro.2008.03.024

26. Hernández D, Cardell E, Zárate V. Antimicrobial activity of lactic acid bacteria isolated from Tenerife cheese: Initial characterization of plantaricin TF711, a bacteriocin-like substance produced by Lactobacillus plantarum TF711. J Appl Microbiol. 2005;99:77-84. https://doi.org/10.1111/j.1365-2672.2005.02576.x

27. Soejima T, Nagao E, Kubota T, Yamagata H, Kagi H. Comparison between ultrafilatation and trichloroacetic acid precipitation method for concentration of Staphylococcus aureus enterotoxin in dairy samples. Int J Food Microbiol. 2004;93:185-94. https://doi.org/10.1016/j.ijfoodmicro.2003.11.005

28. Laemmli UK. Cleavage of structural proteins during the assembly of the head of bacteriophage T4. Nature. 1970:227:680-5. https://doi.org/10.1038/227680a0

29. Charlier C, Cretenet M, Even S, Le Loir Y. Interactions between Staphylococcus aureus and lactic acid bacteria: A old story with new perspectives. Int J Food Microbiol. 2009;131:30-9. https://doi.org/10.1016/j.ijfoodmicro.2008.06.032

30. Rodríguez E, Arqués JL, Gaya P, Tomillo J, Nuñez M, Medina M. Behaviour of Staphylococcus aureus in semi-hard cheese made from raw milk with nisin-producing starter cultures. Milchwissenschaft. 2005;55:633-5. 
31. Alegría Á, Delgado S, Roces C, López B, Mayo B. Bacteriocins produced by wild Lactococcus lactis strains isolated from traditional, starter-free cheeses made of raw milk. Int J Food Microbiol. 2010;143: 61-6. https://doi.org/10.1016/j.ijfoodmicro.2010.07.029

32. Kumari A, Akkoç N, Akçelik M. Purification and partial characterization of bacteriocin produced by Lactococcus lactis ssp. lactis LL171. World J Microbiol Biotechnol. 2012;28:1647-55. https://doi.org/10.1007/s11274-011-0971-4

33. Even S, Charlier C, Nouaille S, Ben Zakour NL, Cretenet M, Cousin FJ, et al. Staphylococcus aureus virulence expression is impaired by Lactococcus lactis in mixed cultures. Appl Environ Microbiol. 2009;75:4459-72. https://doi.org/10.1128/AEM.02388-08

34. Samelis J, Lianou A, Pappa EC, Bogović-Matijašić B, Parapouli M, Kakouri A, Rogelj I. Behaviour of Staphylococcus aureus in culture broth, in raw and thermized milk, and during processing and storage of traditional Greek graviera cheese in the presence or absence of Lactococcus lactis subsp. cremoris M104, a wild, novel nisin A-producing raw milk isolate. J Food Prot. 2014;77:1703-14. https://doi.org/10.4315/0362-028X.JFP-14-105

35. Charlier C, Even S, Gautier M, Le Loir Y. Acidification is not involved in the early inhibition of Staphylococcus aureus growth by Lactococcus lactis in milk. Int Dairy J. 2008;18:197-203. https://doi.org/10.1016/j.idairyj.2007.03.015

36. Le Marc Y, Valík L, Medvedová A. Modelling the effect of the starter culture on the growth of Staphylococcus aureus in milk.
Int J Food Microbiol. 2009;129:306-11.

https://doi.org/10.1016/j.ijfoodmicro.2008.12.015

37. Derzelle S, Dilasser F, Duquenne M Deperrois V. Differential temporal expression of the staphylococcal enterotoxins genes during cell growth. Food Microbiol. 2009;26:896-904. https://doi.org/10.1016/j.fm.2009.06.007

38. Rasooly A, Rasooly RS. Detection and analysis of staphylococcal enterotoxin A in food by Western immunobloting. Int J Food Microbiol. 1998;41:205-12. https://doi.org/10.1016/S0168-1605(98)00050-6

39. Rosengren $\AA$, Lindblad M, Lindqvist $R$. The effect of undissociated lactic acid on Staphylococcus aureus growth and enterotoxin A production. Int J Food Microbiol. 2013,162:159-66. https://doi.org/10.1016/j.ijfoodmicro.2013.01.006

40. Fujikawa H, Morozumi S. Modeling of Staphylococcus aureus growth and enterotoxin production in milk. Food Microbiol. 2006;23:260-7.

https://doi.org/10.1016/j.fm.2005.04.005

41. Terzic-Vidojevic A, Tolinacki M, Nikolic M, Veljovic K, Jovanovic S, Macej O, Topisirovic Lj. Artisanal Vlasina raw goat's milk cheese: Evaluation and selection of autochthonous lactic acid bacteria as starter cultures. Food Technol Biotechnol. 2013;51:554-63.

42. Hamama A, El Hankouri N, El Ayadi M. Fate of enterotoxigenic Staphylococcus aureus in the presence of nisin-producing Lactococcus lactis strain during manufacture of Jben, a Moroccan traditional fresh cheese. Int Dairy J. 2002;12:933-8. https://doi.org/10.1016/S0958-6946(02)00113-9 